\title{
The UK Approach to Greater Market Acceptance of Powered Light Vehicles (PLVs)
}

\author{
Huw Davies, Allan Hutchinson, Richard Barrett, Tony Campbell, \\ and Andy Eastlake
}

\begin{abstract}
This paper summarises the UK activity for powered light vehicles (PLVs) with the purpose of driving market acceptance. If alternative vehicle concepts are to emerge from the margins and transition into the main stream, there is a need to think differently. This opportunity has motivated a number of UK organisations to come together as a working group and identify a way forward. We contend that thinking differently requires a reshaping of the whole value chain. Each of the partners has contributed to this activity and we describe the development of a pathway towards the realisation of a UK PLV market. Research and policy development requirements for the UK market are defined, supported by a discussion on two specific segments of the PLV market-light freight vehicles and micromobility.
\end{abstract}

Keywords Powered light vehicles • UK transport policy • Freight vehicles • Micromobility $\cdot$ Transition pathways

H. Davies $(\square)$

Institute for Future Transport and Cities, Coventry University, Coventry, UK e-mail: ac2616@coventry.ac.uk
A. Hutchinson
School of Engineering, Computing and Mathematics, Oxford Brookes University, Oxford, UK
R. Barrett
School of Engineering, Liverpool University, Liverpool, UK
T. Campbell
Motor Cycle Industry Association (MCIA), Coventry, UK
A. Eastlake
Low Carbon Vehicle Partnership, London, UK
(C) The Author(s) 2021 


\section{Introduction}

In the UK, surface transport is the largest sector contributor to GHG emissions [1], urban road speeds have reduced by almost $5 \%$ in the past 4 years to $18.7 \mathrm{mph}$ [2], whilst nine out of ten Londoners say air pollution is at crisis level [3]. In responding to the problems of climate change, congestion and air quality, it is increasingly recognised that there is a need to re-evaluate our transport options and energy sources for them.

Smaller, lighter, and more energy efficient vehicles are seen as an alternative to traditional mobility options, especially where a move towards other existing forms of transport or a reduction in transport provision is not a viable alternative. The dichotomy is that these alternative concepts are currently perceived as inferior to traditional mobility solutions, resulting in marginalisation and disbenefits to the supplying industry. Further, those vehicle concepts that are more radical in approach also have the issue of public perception to overcome, including functionality issues and concerns about safety.

Transforming the individual vehicle we drive today will require several changes in a holistic sense:

- electric variants;

- the creation of an environment whereby smaller more efficient vehicles can provide a defined benefit;

- changing society to see the value of the most appropriate vehicle for a particular journey;

- supporting suppliers to invest in the development and manufacture of alternative smaller vehicles.

It is the purpose of the UK PLV Working Group to support these changes and provide a forum for co-ordination of activities in this area.

\section{Background}

Within the UK, and when compared to a number of EU member states, the market penetration of smaller vehicles - those below the M1 passenger car classificationhas been limited. Collectively, this category of vehicles is referred to as L-category and consists of powered 2 and 3 wheel vehicles, quadricycles, and microcars. This includes motorbikes and scooters which account for the largest part of the current L-category market.

Although there are relatively few L-category vehicles compared to $\mathrm{M}$ and $\mathrm{N}$ categories (passenger and goods vehicles) in the UK, they are much smaller, lighter, take up less road space and offer innovative alternatives for mobility, particularly in cities. This engenders the L-category to those concerned with finding solutions to 
the current externalities around road transport, in particular the pressure on cutting energy consumption, improving local air quality and reducing local congestion.

Recognising this, in 2015, a study into the potential of the L-category market for the UK automotive industry was initiated. This study linked the LowCVP, the UK DfT, and six UK universities: Loughborough, Cardiff, Coventry, Oxford Brookes, Queen's Belfast, and Warwick. The study was broad ranging and recognised that the issue of L-category vehicles was a combination of producer, consumer, and societal interests. Hence, the impacts and benefits were equally wide ranging and considered: air quality and GHG; economic activity including cost to the industry as well as the consumer; and public health including road safety. The result of this study was the launch of the report "Powered Light Vehicles: Opportunities for Low Carbon 'L-Category' Vehicles in the UK' in 2019 [4].

The main conclusion of the Consortium was that PLVs - with either an electric or highly efficient internal combustion engine powertrain - create an opportunity to provide an important contribution to reduction in polluting emissions and energy consumption, both during the manufacture and subsequent operation of these vehicles in the UK. Furthermore, PLVs offer potential growth opportunities for the UK industry, building on the existing engineering capabilities of the automotive sector and, in particular, the motorcycle, motorsports, and niche vehicle sectors, which are well-positioned to exploit opportunities for this category of vehicle. The PLV consortium assessment also identified a number of challenges to the manufacture and use of PLVs in the UK. These relate to the delineation of regulations relating to sit-on and sit-in vehicles, and the incorporation of PLVs into existing UK and EU policy frameworks. The full series of reports written by consortium members are available for further background information and can be downloaded from the LowCVP website: www.LowCVP.org.uk/PLV.

Further to the above activity, the UK Motor Cycle Industry Association (MCIA) has also played an active role in support of the PLV sector in the UK. The MCIA is the Trade Association representing the PLV industry (also known as L-Category vehicles) and has created this strategy to highlight the benefits of incorporating PLVs into the transport mix. As part of its remit, and summarised in the joint publication with the LowCVP "The Route to Tomorrow's Journeys: Powered Light Vehicles - Practical, Efficient \& Safe Transport for All”, are the results of a number of studies investigating the benefits to the UK of supporting the PLV sector [5]. The benefits of these have been explained in full, including the impressive results of the congestion impact and air quality study. Unsurprisingly, the results showed that with a greater shift to electric PLVs (L-category vehicles that have battery electric drivetrains), fewer $\mathrm{NO}_{\mathrm{X}}$ emissions will be recorded (from $0.48 \mathrm{~kg} / \mathrm{day}$ for the chosen baseline scenario to $0.42 \mathrm{~kg} /$ day with a $10 \%$ modal shift). Reductions were also seen in the scenarios showing the modal shift for $\mathrm{PM}_{10}$ and $\mathrm{PM}_{2.5}$ (from 0.093 to $0.087 \mathrm{~kg} /$ day and 0.051 to $0.048 \mathrm{~kg} /$ day, respectively). Emissions relate to the carbon intensity of the electricity grid, and the increasingly renewable content of the UK grid mix (50\% in 2019 [6]) means that considerable further reductions may be anticipated in future. Furthermore, the modelled scenarios also found that congestion levels decreased, resulting in reduced delays and shorter journey times for 
everyone across nine real world junctions (a 20\% modal shift gave an $18.4 \mathrm{~s}$ reduction in delay averaged across all junctions improving to $39.8 \mathrm{~s}$ for a $50 \%$ modal shift).

Realising the joint interest in the promotion of PLV in the UK, the MCIA partnered with LowCVP in the UK launch of the "The Route to Tomorrow's Journeys: Powered Light Vehicles - Practical, Efficient \& Safe Transport for All" and 'Powered Light Vehicles: Opportunities for Low Carbon 'L-Category' Vehicles in the UK' at the London Transport Museum in 2019. The launch was in response to the UK Government publication of the "Future of Mobility: Urban Strategy" [7]. This strategy document recognised that the rise of motor transport has brought substantial benefits, the strategy document also warned that high levels of private car ownership and use have also brought serious challenges. In response the vision articulated in the strategy:

cleaner transport, automation, new business models and new modes of travel [that] promise to transform how people, goods and services move.

To support that UK Government vision and to position PLV as part of that vision, a new UK PLV working group was established in 2019. The working group is chaired by Coventry University with the MCIA as the secretariat and has the LowCVP, Oxford Brookes University and Liverpool University as permanent members. This group looks to take forward the previous recommendations and discussion points from both the PLV consortium and the MCIA activities. The group has set itself the following mission statement:

Movement of individuals and goods facilitates production and trade, enhances labour mobility and provides customers with access to goods. Reducing transport-related climate emissions will require transformational changes in thinking, policy, technology and investment to enact. Lighter and smaller vehicles are a key part of the solution (powered light vehicles - PLVs), but struggle to find UK market acceptance. Developing collaborations in research and policy development is a timely intervention to support this.

\section{Path to System Transformation}

PLVs can play a valuable role in the local transport mix. The recent UK MCIA policy document The Route to Tomorrow's Journeys, refers to a modal shift away from single-occupancy cars and lightly laden vans, towards transport modes that take up less road space and use less energy. The key is to encourage the use of 'the right vehicle for the right journey' and to support transport users in making appropriate choices. However, this transition to the right vehicle for the right journey has proven difficult to realise. It is the inter-relationships between the different parts of the mobility system that can create a resistance to change, resulting in customer lock-in, for example, the economies of scale resulting from the mass adoption of one type of transport modality can cascade through the system reinforcing the existing support structures and locking out modalities that rely on 
alternative structures. It is understanding and managing these relationships, or how component changes impact upon them, that is key to transformation of our mobility system. For PLVs to move from niche to mainstream, acceptance will require concurrent changes in different parts of the system.

Before alternative mobility solutions, such as the wide spread adoption of PLVs, become widely accepted and economically competitive, they are required to overcome such barriers as technology inter-relatedness, vested interests, legal frameworks that fit the use of historical and present technologies, and the limitations imposed by the evolved consensus over how technology should be designed limiting the vision of business and governments [8]. Existing regulation for PLV application is complex and because traffic laws are defined on national level, different rules are applied across European member states and the UK. Driving licences, for example, are regulated on EU level, but exceptions are permitted for member states for some parameters, for example minimum driving age [9]. Based on this understanding, an exclusively technology-focused approach is unlikely to provide the change required, but it can be an important component.

In response to the research challenge, the PLV Working Group seeks to engage the engineering with the social, economic and planning aspects of the market. The objective is to use a multidisciplinary approach to understand the risk to investment in the emerging PLV value chain in the UK and in the EU. This understanding will inform the development of a framework that will support and strengthen the formulation of technology and public policy to reduce investment risk and strengthen the development, deployment, and diffusion of PLV technologies.

Policy instruments themselves may address a number of market imperfections. However, the way in which national and local governments use these instruments is highly contextualised. First, there is an enormous diversity of policy measures with regards to PLVs in the UK. This alone is indicative of the fact that there is great uncertainty over what works. Second, in terms of socio-technical transitions, the underlying imperative is to stimulate the change process, and yet the uncertainty over policy tools may hinder or even obstruct the change process, because the policy development is primarily evidence based. This presents a number of problems when discussing PLVs. The first is that there is a paucity of evidence upon which to base policy. The second is the variation in vehicle types that exist in different regions due to regulatory frameworks.

It is the inter-relationships between the different parts of the mobility system that can create resistance to change. It is understanding and managing these relationships, or how component changes impact upon them, that is key to transformation of the mobility system. For PLVs to move from niche to mainstream, acceptance will require concurrent changes in different parts of the system. To demonstrate this, two cases are presented from the UK perspective. One, the case of micromobility, is used to demonstrate where existing policy creates customer lock-in, by excluding alternative forms of emerging mobility acceptable to the market place. The other, light freight vehicles, is used to demonstrate where a potential market shift could be supported by appropriate co-ordination of technology and public policy. 


\subsection{Case 1: Micromobility and the UK}

Micromobility is an ambiguous term associated with a rapidly evolving range of powered light vehicles that are increasingly populating streets across the globe (see Fig. 1).

In the United Kingdom and Ireland, these types of motorised micro-vehicles are simply excluded from public roads (and pavements) until the definitions of vehicles permitted for use on the road are updated to include them.

The questions challenging national and local policy makers include:

- Should they be licensed on a technology-specific basis or on a more general mass, power and speed basis?

- Where should they be allowed to operate?

- Will infrastructure need to be adapted to allow for their safe use?

- Which traffic safety requirements should national and local authorities place on shared micromobility operators?

More recently the UK government has opened a call for evidence specifically targeting the micromobility sector. "The Future of Transport Regulatory Review Call for Evidence" published in March 2020 asks:

How, for instance, can e-scooters make life cheaper, more convenient, and maybe a bit more exciting? But also: how safe are they, for their riders and for other road users, and how sustainable? Will they really reduce traffic, or will they reduce walking and cycling more? [9].

Within the UK, the MCIA, a partner in the UK PLV working group, has been active on proposing solutions to the above. Firstly, the specification of the e-scooters used in the UK trials can provide a basis for a framework to categorise e-scooters. Secondly, this framework - and suitably developed according to the findings of those trials - will inform any future legal specification for those wishing to purchase an e-scooter. This approach provides the foundation for making these vehicles accessible-provided that accompanying changes are introduced to

Fig. 1 Examples of the types of vehicle that MCIA believes would come under the scope of micromobility (own visualisation)
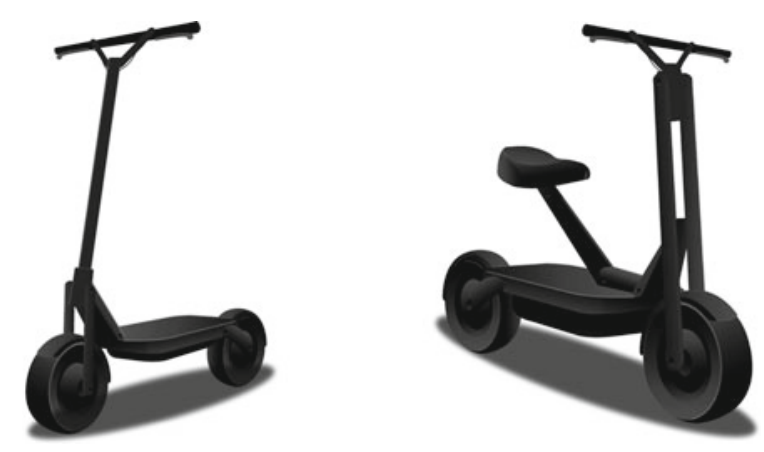
licensing [10], training and personal protective equipment (PPE), etc. Further, such an approach also provides an additional level of certainty to the supplying industry that leads to increase in product availability and diversity.

\subsection{Case 2: Powered Light Vehicles for Freight and the UK}

Receiving goods is an essential component of business, but these deliveries are also a large contributor to congestion and air pollution. This is acknowledged as part of the UK Government's Future of Mobility: Urban Strategy [7]:

There is significant potential for new modes of transport to replace traditional vehicle miles in urban areas. This could alleviate congestion, reduce noise and emissions, and improve traffic flow. For example, trials of electric cargo bikes showed that they have the potential to increase road speeds in congested areas as well as reducing emissions, costs and delivery times when compared to van-based last mile delivery

Innovation that supports the more efficient movement of goods, for instance through the use of consolidation hubs or freight brokerage platforms matching goods and vehicle space, will also be important to reduce congestion.

The advantages of using PLV, for example, electric cargo bikes, in arriving at a clean and safe system for the delivery of goods should be fully explored and considered as part of a wider transport strategy and local authority provision. However, the reality is slightly different. Within the UK, a PLV freight sector remains an enigma when compared to the wider light commercial vehicle (LCV) fleet. To understand this underrepresentation requires a closer examination of the finer nuances of how a PLV freight sector would function in the UK. For any new mobility concept, the requirement is

- that it finds alignment with policy;

- that it is economically viable;

- that is accepted by society;

- that industry has the incentive to invest;

- that it is in step with the environment into which it is deployed;

- and that ambiguity over its legal status is addressed.

Concepts that promote a new technology, but fail to consider the economics or the legal status within the market fail to achieve that system transformation. Concepts that promote a new business model, but fail to provide the technology to support that business model, or do not engage with the consumer, fail to achieve that system transformation. Concepts that promote new approaches to manufacture, but fail to consider the wider role of policy in promoting and sustaining existing approaches fail to achieve that transformation. However, the introduction of concurrent concepts that maintain or strengthen inter-dependencies between the various factors can lead to a system transformation. Taking a new vehicle concept and changing the 
retail environment to account for the different unit cost can succeed. Taking a new mobility concept and changing the regulatory environment can engage with the consumer and succeed.

In the UK context, PLVs used for freight can be considered a new product. Indeed, with their radically different composition (payload, performance, cost base, etc.) and the substantial change, this requires to business systems and accompanying value chains, it can be argued that PLVs would also constitute a new industry. In this context, success requires that technology change has to be partnered by a change to business models, and of course needs customer acceptance. This has higher risk and generates resistance to change.

In response, the acceptance and the success of PLVs for freight will depend strongly on identifying effective use cases that provides user friendly and economic viable operation. New policy and legislative measures can then be introduced that will support the provision of these use cases. For example, the introduction of special operational specifics of L-category traffic regulations like use of bicycle lanes, pedestrian zones or reverse one-way driving. These are presently excluded in the UK for most of the PLV solutions that would be suitable for the type of freight deliveries envisaged by the UK Government strategy document. Further, enabling such special operational specifics, and ensuring there is a level of stability associated with these changes, would also have the benefit of supporting the freight sector in identifying and quantifying risks with new business models that can inform its business planning and forward investment. Factors influencing economic operations include appropriate licensing arrangements, financial incentives and operational motivations such as privileged access, low running costs, and so on.

At present, business models around the use of PLV for freight are generally insufficient, which restrict the development of this sector outside of their core (niche) markets. Current and evolving policy frameworks, that enable special operational specifics, will speed up the adoption and expansion of the PLV for freight. To support this requires regulatory change, which will have the outcome of creating new market spaces. The UK PLV Working Group will be active in this area.

\section{Discussion}

Replace existing modalities with PLVs has the potential to generate a range of positive outcomes, from clean air to reduced congestion. Hence, there is strategic value in the support of PLVs and this has been recognised in the UK strategy for urban mobility. However, with such a complex system as road transport, the interventions in support of a move to PLVs must be planned and must be co-ordinated in order to support wider market acceptance. This paper has summarised the UK activity for PLVs with the purpose of driving market acceptance. 
It has also been shown how the activity links to the UK strategy for future urban mobility. Further to the above, a result of this activity has been the identification of a number of key recommendations and discussion points. These are summarised below:

Key recommendations:

- Raise awareness among key stakeholder within the UK value chain

- Undertake whole life-cycle assessments of PLVs

- Make representations at EU level to include PLVs in fleet averages,

- Implement technical R\&D projects needed to optimise systems applicable PLVs

- Conduct UK focused end-user research to build on the insights from early adopters

- Re-assess UK low-carbon vehicle purchase incentives to include PLVs.

Discussion points:

- Currently only M, N, and O category vehicles are supported by the National Small Series Type Approval (NSSTA) in the UK. To assist small UK companies in entering the PLV market, the UK Department for Transport (DfT), along with the Vehicle Certification Agency (VCA), is to consult stakeholders on creating a NSSTA for PLVs.

- Improve regulatory delineation between open "sit-on" and enclosed "sit-in" L-category powered light vehicles. The former (scooters, motorcycles, quadbikes) are already an established market, whereas the latter has neither a clear identity for consumers (e.g. safety standards) nor the best legal framework (e.g. suitable drive cycle/crash test procedures) to flourish.

- New regulations are needed for a minimum safety cell performance: frontal and side impact crash tests performance (appropriate for the class), rollover test, seat with whiplash protection. Impact test for pedestrians (enhancement of existing functional safety regulations). Further accident research performed on L-category PLVs to review and amend the initial test proposed for the frontal, lateral, and roll-over load cases.

- Funded research is undertaken to ensure that future vehicles of all sizes are able to detect PLVs in their AEB sensing algorithms. Along with funded research in the development of AEB, city, inter-city and pedestrian safety and funded research into the implementation of an integrated safety test protocol of L-category PLVs.

To deliver against these recommendations and to support ongoing discussion, a UK PLV working group has been established. To date the working group has focused on two emerging PLV sectors: micro-mobility and freight.

- For micro-mobility, an emerging consumer demand is at present tempered by a gap in the classification of the product. A recommendation for classification that extends the existing L-category topology is proposed. Adoption by Government 
would enable the appropriate discussion around category definition-taking into account concerns around safety in addition to congestion and emission benefitswhich would in turn lead to increased consumer confidence and industry participation.

- For freight, the issue is that the business models around PLVs are generally insufficient outside of specific niche applications. The adoption of PLVs will depend strongly on expanding the effective use case through a combination of product innovation and creating new market spaces through a change in surrounding conditions, such as creating specific regulations like use of bicycle lanes, pedestrian zones or reverse one-way driving. An effective use of these specific regulations may be viewed as a key enabler for new delivery services.

\section{Next Steps}

Following on from the recently announced UK government call for evidence on transport regulation and specifically targeting the micromobility sector [9], a further publication of 26 March 2020 "Decarbonising Transport, Setting the Challenge" [11] states:

We will use our cars less and be able to rely on a convenient, cost-effective and coherent public transport network. From motorcycles to HGVs, all road vehicles will be zero emission. Technological advances, including new modes of transport and mobility innovation, will change the way vehicles are used. Our goods will be delivered through an integrated, efficient and sustainable delivery system

The strategic position of the UK government - outlined in the call for evidence on transport regulation and the decarbonisation challenge-creates a clear opportunity for the development of a robust and optimised PLV market within the future of UK transport and will form a continuing basis for further coordination of the UK PLV group.

\section{References}

1. Committee on Climate change: Reducing UK emission - 2019 progress report to parliament. https://www.theccc.org.uk/publication/reducing-uk-emissions-2019-progress-report-toparliament/ (2019). Last Accessed 6 Nov 2019

2. Department for Transport: Transport Statistics Great Britain 2017, https://assets.publishing. service.gov.uk/government/uploads/system/uploads/attachment_data/file/664323/tsgb-2017print-ready-version.pdf (2017). Last Accessed 20 Sep 2018

3. London.Gov: 9/10 Londoners say air pollution is at 'crisis' levels. https://www.london.gov. uk/press-releases/mayoral/londoners-poll-air-pollution-is-at-crisis-levels (2017). Last Accessed 13 Nov 2017 
4. LowCVP: Micro vehicles: opportunities for low carbon 'L-Category' vehicles in the UK. https://www.lowcvp.org.uk/assets/reports/LowCVP_Powered_Light_Vehicles_2019. pdf\&usg=AOvVaw0MLVstf3OX_PqdfrhtvPwC (2019). Last Accessed 1 May 2020

5. MCIA: The route to tomorrow's journeys: powered light vehicles - practical, efficient \& safe transport for all. https://mcia.co.uk/attachment/ead15463-d738-4dd0-a43d-bc48ca633fb7 (2019). Last Accessed 1 May 2020

6. Raugei, M., Kamran, M., Hutchinson, A.: A prospective net energy and environmental life-cycle assessment of the UK electricity grid. Energies 13(9), 2207 (2020)

7. DfT: Future of mobility: urban strategy. https://assets.publishing.service.gov.uk/government/ uploads/system/uploads/attachment_data/file/846593/future-of-mobility-strategy.pdf (2019). Last Accessed 1 May 2020

8. Sanden, B.A., Azar, C.: Near-term technology policies for long-term climate targetseconomy wide versus technology specific approaches. Energy Policy 33, 1557-1576 (2005)

9. DfT: Future of transport regulatory review: call for evidence. https://assets.publishing.service. gov.uk/government/uploads/system/uploads/attachment_data/file/873363/future-of-transportregulatory-review-call-for-evidence.pdf (2020). Last Accessed 5 May 2020

10. Directive 2006/126/EC of the European Parliament and of the Council of 20 December 2006 on driving licences

11. DfT: Decarbonising transport: setting the challenge'. https://assets.publishing.service.gov.uk/ government/uploads/system/uploads/attachment_data/file/878642/decarbonising-transportsetting-the-challenge.pdf (2020). Last Accessed 5 May 2020

Open Access This chapter is licensed under the terms of the Creative Commons Attribution 4.0 International License (http://creativecommons.org/licenses/by/4.0/), which permits use, sharing, adaptation, distribution and reproduction in any medium or format, as long as you give appropriate credit to the original author(s) and the source, provide a link to the Creative Commons license and indicate if changes were made.

The images or other third party material in this chapter are included in the chapter's Creative Commons license, unless indicated otherwise in a credit line to the material. If material is not included in the chapter's Creative Commons license and your intended use is not permitted by statutory regulation or exceeds the permitted use, you will need to obtain permission directly from the copyright holder.

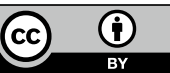

